DOI: https://doi.org/10.24867/14BE10Ljubojev

\title{
PRORAČUN HOSTING CAPACITY-A U SREDNJENAPONSKOJ DISTRIBUTIVNOJ MREŽI
}

\section{CALCULATION OF THE HOSTING CAPACITY IN MEDIUM VOLTAGE DISTRIBUTION NETWORK}

\author{
Nataša Ljubojev, Fakultet tehničkih nauka, Novi Sad
}

\begin{abstract}
Oblast - ELEKTROTEHNIKA I RAČUNARSTVO
Kratak sadržaj - U ovom radu prikazan je pristup za određivanje Hosting Capacity-a u distributivnoj mreži. Cilj je da se ispita uticaj različitih faktora na Hosting Capacity, kao što su različiti indeksi performansi, njihova ograničenja, ali i uticaj proizvodnje i potrošnje. Verifikacija problema izvršena je na srednjenaponskoj distributivnoj mreži od 15 čvorova.
\end{abstract}

Ključne reči: Distribuirana proizvodnja, Hosting Capacity, Distributivna mreža

Abstract - This paper present the approach for Hosting Capacity calculation in the distribution network. The goal is to investigate the impact of different factors on the Hosting Capacity, as index performances, their limits and impact of generation and load. Verification of results was carried out on medium voltage network with 15 buses.

Keywords: Distribution generation, Hosting Capacity, Distribution network

\section{UVOD}

Uvođenje distribuirane proizvodnje uticaće na performanse distributivne mreže. Odnosno, dodavanje nove proizvodnje ili potrošnje u distributivnu mrežu uticaće na tokove snaga, kvalitet napona, struju kratkog spoja i druga svojstva mreže.

Distribuirana proizvodnja pruža brojne prednosti, jer može smanjiti prenos energije između regiona elektroenergetskog sistema i neravnotežu energije u svakom regionu, dok, takođe, može omogućiti ravnomernu raspodelu celokupnog sistema, tako što brzo reaguje na promenu zahteva.

S druge strane, preterana penetracija distribuirane proizvodnje u električne mreže može dovesti i do različitih problema i narušavanja operativnih ograničenja, kao što su prenaponi i podnaponi, prekomerni gubici na vodovima, preopterećenja transformatora i vodova, kvara zaštite i visokog nivoa harmoničnih izobličenja koji prelaze ograničenja međunarodnih standarda.

Veoma bitno pitanje za industriju distributivne mreže je količina distribuirane proizvodnje koju određena distribu-

\section{NAPOMENA:}

Ovaj rad proistekao je iz master rada čiji mentor je bio dr Andrija Sarić, red. prof. tivna mreža može može apsorbovati bez ikakvih narušavanja radnih ograničenja u pogledu napona, opterećenja komponenti i snage kratkog spoja. Stoga je osnovno pitanje kako postojeći distributivni sistemi treba da se prilagode na dodavanje više distribuiranih izvora energije bez neprihvatljivih negativnih uticaja na potrošače i performanse mreže.

$\mathrm{Na}$ ova pitanja utiče niz različitih faktora, kao što su struktura distributivne mreže, zavisnost od lokacije generatora i, konačno, neizvesnosti koje sa sobom donosi distribuirana proizvodnja.

Kao odgovor na prethodno pomenute probleme i pitanja, koji će odlučiti kada treba prihvatiti ili odbiti novu integraciju distribuiranih generatora (DG) u postojeću distributivnu mrežu, uveden je koncept "Hosting Capacity", koji je i tema ovog rada. Razumevanje ovog koncepta može pomoći operatorima da donesu odluke $\mathrm{u}$ vezi sa zahtevima za međusobno povezivanje kako bi osigurali pouzdan rad sistema.

\section{HOSTING CAPACITY}

Hosting Capacity je maksimalna količina proizvodnje ili potrošnje koja se može dodati na određenu lokaciju, fider, na deo elektroenergetskog sistema ili na elektroenergetski sistem u celini, a da ne dođe do prekoračenja jednog ili više operativnih limita, koji se mogu nazvati indeksima performansi [1].

\subsection{Indeksi performansi}

Svaka pojava na koju utiče dodavanje DG-a (napon, struja, zaštita itd.) mora se modelovati nizom indeksa performansi koji će imati definiciju svojih granica, tj. prihvatljivo odstupanje. Hosting Capacity je zasnovan na tome. To znači da izbor indeksa performansi i ograničenja ima veliki uticaj na količinu distribuirane proizvodnje koja se može priključiti.

U nekim slučajevima performanse mreže će se poboljšati nakon povezivanja distribuirane proizvodnje, a u drugim slučajevima će se pogoršati za povezane potrošače. Pogoršanje napajanja nije direktno briga, sve dok je rezultirajući kvalitet u prihvatljivom opsegu. Drugim rečima, za svaki indeks performansi postoji ograničenje koje ne bi trebalo da bude prekoračeno. Prekoračenje može dovesti do preopterećenja komponente, skraćivanja radnog veka komponenti ili, u najgorem slučaju, dovodi do kvara sistema [1]. 
Hosting Capacity se definiše kao količina distribuirane proizvodnje za koju performanse postaju neprihvatljive.

U praksi se definišu mnogi indeksi performansi, tako da niža vrednost odgovara boljim performansama. Ovo je ilustrovano na slici 2.1. Kako se iznos proizvodnje povećava, indeks performansi se pogoršava. Hosting Capacity je, ne kada performanse počnu da se pogoršavaju, već kada pogoršanje postane neprihvatljivo.

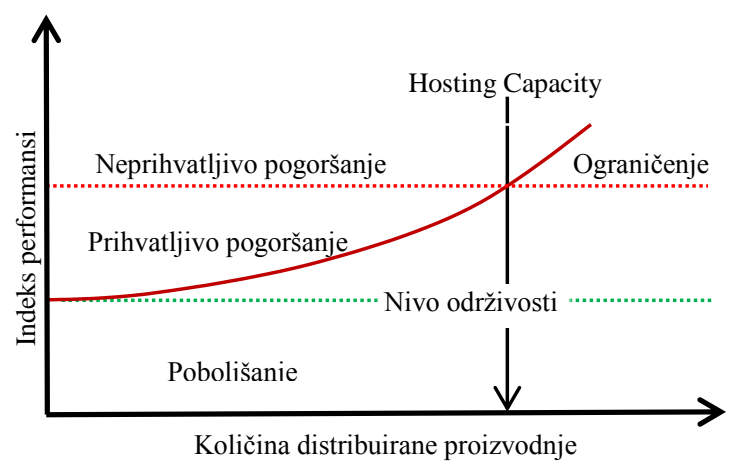

Slika 2.1 Hosting Capacity pristup [1]

Postoji više indeksa performansi koje treba uzeti u obzir prilikom priključivanja distribuiranih izvora $u$ distributivni sistem u cilju definisanja Hosting Capacity-a. To su: naponske granice, preopterećenje voda, ograničenja transformatora, obrnuti tokovi snaga na regulacionoj sklopci transformatora, granice zaštite kratki spojevi, kvalitet napona (flikeri,harmonici) i drugi. Moguće je uzeti u obzir jedan ili više indeksa performansi, u zavisnosti od toga koji se efekti distribuirane proizvodnje žele detaljnije ispitati. Na slici 2.2 prikazan je Hosting Capacity za slučaj kada se uzima u obzir više indeksa performansi i njihovih ograničenja. Najniži od ovih Hosting Capacity-a predstavlja maksimalan kapacitet koji se može dodati sistemu pre nego što se moraju uložiti dodatne investicije [2].

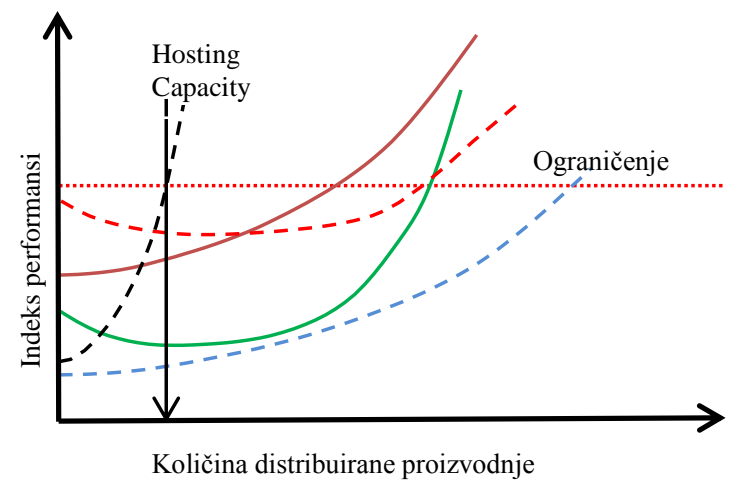

Slika 2.2 Hosting Capacity za više indeksa performansi [2]

\section{ALGORITAM ZA PRORAČUN HOSTING CAPACITY-A}

Blok dijagram algoritma za proračun Hosting Capacity-a po čvorovima je prikazan na slici 3.1. Hosting Capacity se računa za svaki čvor postepenim povećavanjem količine DG-a u malim inkrementalnim koracima (npr. $1 \mathrm{~kW}$, $10 \mathrm{~kW} . .$.$) u svakom čvoru dok se ne naruši jedan od$ indeksa performansi. Analiza tokova snaga vršiće se nakon svakog dodavanja DG-a. Napon, struja i snaga se porede sa maksimalnom dozvoljenom vrednošću nakon svakog proračuna tokova snaga, kako bi se proverilo da li mreža još uvek ima kapacitet za veću penetraciju. Nakon svakog dodavanja DG-a u čvor, treba uporediti nova stanja napona i struja sa početnim stanjem (a ne sa prethodnim nižim stanjem DG-a) topologije mreže bez ikakve penetracije DG-a. Ako nije narušeno nijedno ograničenje, DG će se dodavati i svi proračuni će se ponoviti. Dodavanje DG-a će se nastaviti sve dok ne bude prekoračeno jedno od definisanih ograničenja.

U slučaju da je došlo do prekoračenja, količina distribuirane proizvodnje u tom čvoru smanjuje se za jednu veličinu inkrementalnog koraka i poslednja vrednost pri kojoj nisu bila narušena ograničenja će se smatrati Hosting Capacity-em u čvoru koji se trenutno razmatra. Nakon toga se prelazi na naredni čvor, određuje se Hosting Capacity za njega i tako za sve čvorove mreže.

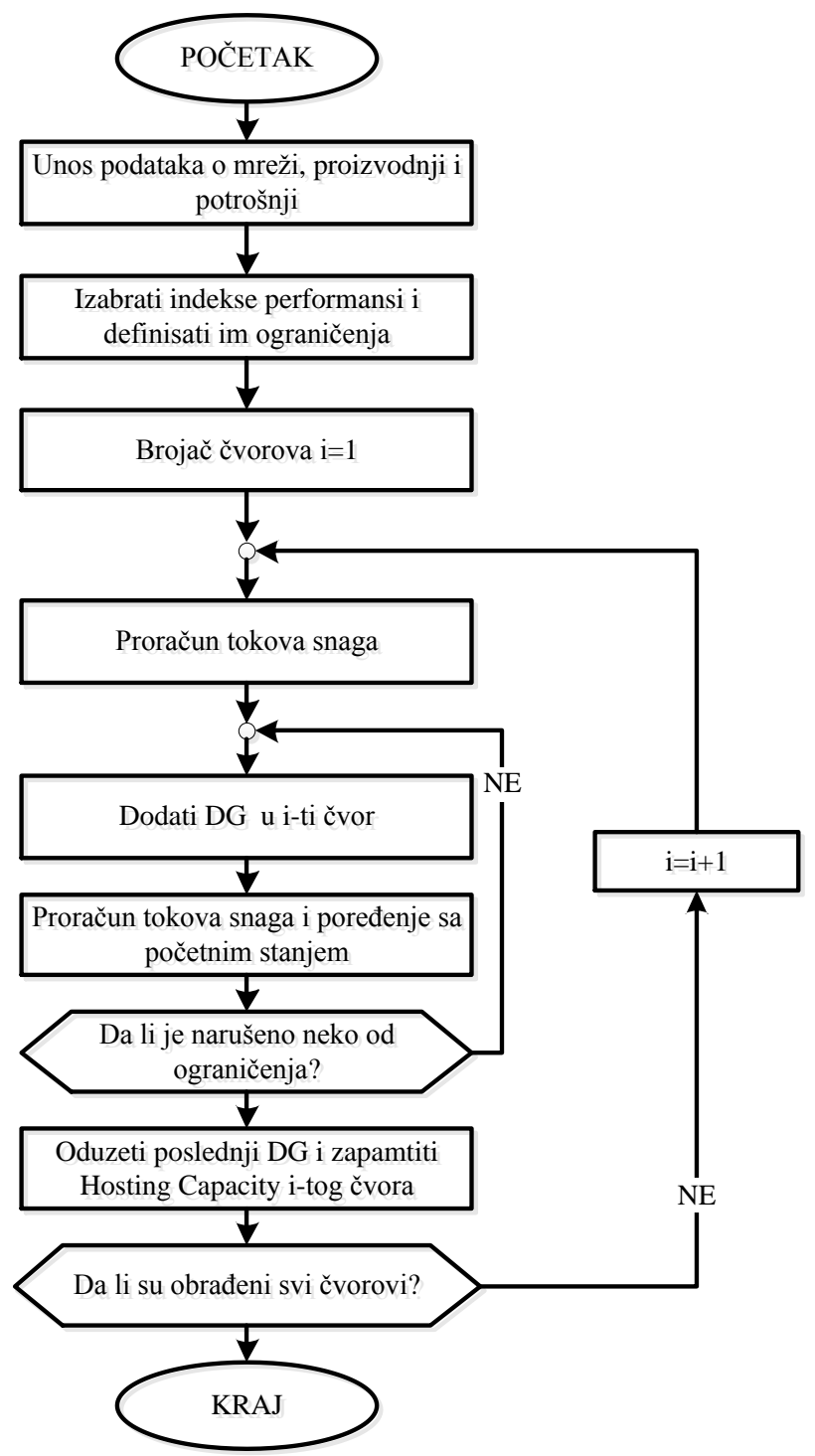

Slika 3.1 Blok dijagram za proračun Hosting Capacity-a

\subsection{Odabir ograničenja za indekse performansi}

Indeksi performansi koji će se koristiti u ovom radu su ograničenja napona, strujna ograničenja vodova i ograničenja transformatora.

Ograničenje napona - Specificirano je da naponi treba da ostanu u $10 \%$ nazivnog napona tokom $95 \%$ vremena godišnje kako bi se izbegli problemi sa stabilnošću i 
kvarovi na mreži. Da bi to postigli, operatori tokom faze planiranja koriste kriterijume za statički porast napona:

$$
\Delta V \leq \epsilon_{\max }
$$

gde je uzeto da je $\epsilon_{\max } 3 \%$ za srednjenaponsku mrežu.

$\Delta \mathrm{V}$ je odstupanje napona po čvoru od napona nakon što je injektiranje DG-a umanjeno za napon istog čvora tokom početnog scenarija bez DG-a. Takođe, ni pad napona se sme da bude veći od $3 \%$ [3].

\section{Strujna ograničenja voda}

Što se tiče vodova u distributivnoj mreži, u skladu sa transformatorima, postoji nekoliko maksimalnih vrednosti po struji koje se ne smeju premašiti, kako bi se izbeglo oštećenje nekoliko komponenti u mreži ili kratki spojevi. Za ova ograničenja postoji nekoliko prikaza koji se odnose ili na struje kroz vodove, ili na očigledna ograničenja snage. U ovoj formulaciji usvojena je reprezentacija prividne snage i kao rezultat ograničenje se može izraziti formalno kao:

$$
S_{i j}=\sqrt{P_{i j}^{2}+Q_{i j}^{2}} \leq S_{i j}^{\max }
$$

\section{Ograničenje transformatora}

Da se ne bi pogoršao preostali životni vek transformatora, prividni tok snage kroz prenosni transformator mora biti manji ili jednak maksimalnom prividnom ograničenju snage na osnovu nominalnih vrednosti. Ograničenje se može izraziti formalno kao:

$$
S_{T R}=\sqrt{P_{T R}^{2}+Q_{T R}^{2}} \leq S_{T R}^{\max }
$$

\subsection{Hosting Capacity fidera}

Hosting Capacity fidera nije pojedinačna vrednost. Generalno, mogu se definisati tri regije, kao što je prikazano na slici 3.2

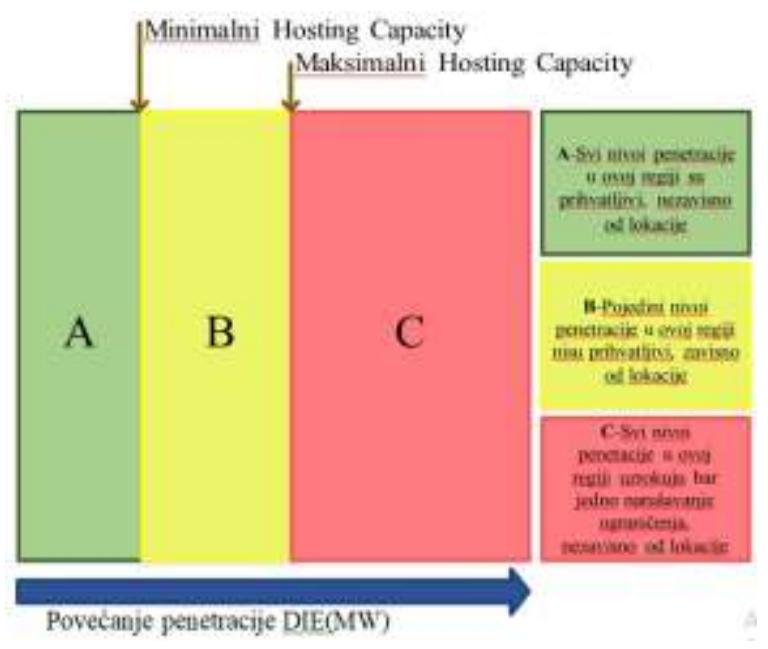

Slika 3.2 HC fidera [4]

Regija (A) uključuje sve nivoe penetracije koji ne izazivaju narušavanje ograničenja, bez obzira na lokaciju DG-a. Regija (B) pokazuje nivoe penetracije koji su prihvatljivi na određenim mestima duž fidera. Regija (C) uključuje sve nivoe penetracije DG-a koji nisu prihvatljivi, bez obzira na lokaciju DG-a. Granica između
(A) i (B) je definisana kao minimalna vrednost Hosting Capacity -a, a granica između (B) i (C) je definisana kao maksimalna vrednost Hosting Capacity-a.

\section{VERIFIKACIJA PRORAČUNA}

Svi proračuni su se izvodili na CIGRE srednjenaponskoj distributivnoj mreži, koja je prikazana na slici 4.1.

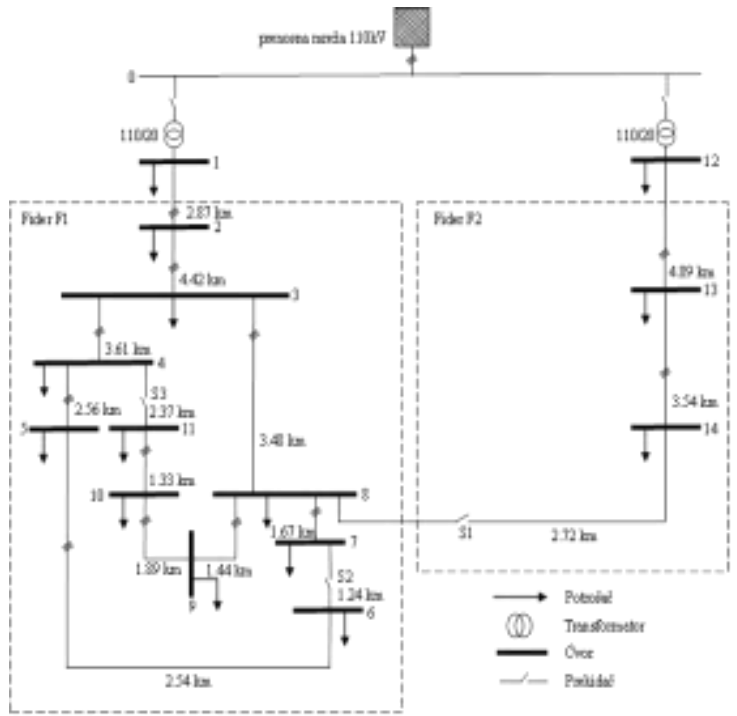

Slika 4.1 CIGRE distributivna test mreža [5]

\section{Primer 1}

U prvom primeru računa se Hosting Capacity po svim čvorovima mreže. Generatori rade sa jediničnim faktorom snage. Proračun se vrši za slučaj kada je proizvodnja maksimalna, a potrošnja minimalna. Ograničenja napona su $\pm 3 \%$, dok su strujna i ograničenje transformatora $50 \%$. Rezultati proračuna su prikazani na slici 4.2.

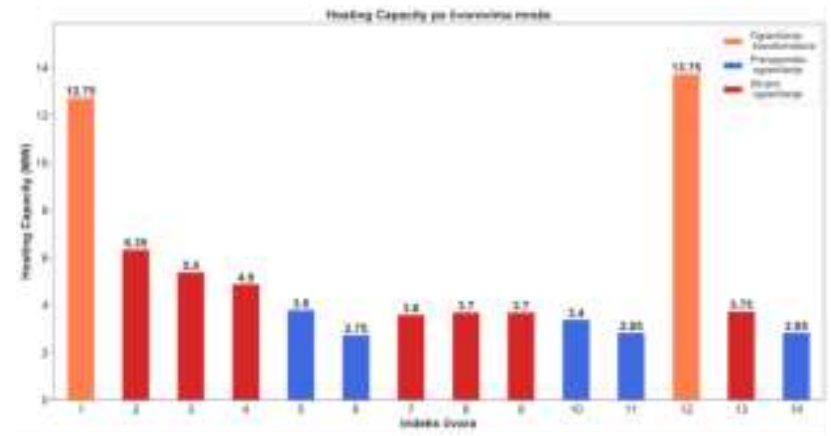

Slika 4.2 Hosting Capacity po čvorovima mreže za primer 1

U čvorovima 1 i 12 može da se priključi najveća snaga DG-a, a da ne dođe do narušavanja ograničenja transformatora. Najmanje vrednosti Hosting Capacity-a su dobijene u čvorovima 5, 6, 10, 11 i 14, jer su to čvorovi koji su najudaljeniji od transformatora, pa će u njima najpre doći do porasta napona. U preostalim čvorovima će najpre doći do narušavanja strujnog ograničenja, što je posledica toka aktivne snage od DG-a ka mreži.

\section{Primer 2}

U drugom primeru se računa Hosting Capacity po svim čvorovima mreže. Generatori rade sa jediničnim faktorom snage. Proračun se vrši za slučaj kada je proizvodnja minimalna, a potrošnja maksimalna. Rezultati proračuna su prikazani na slici 4.3 . 


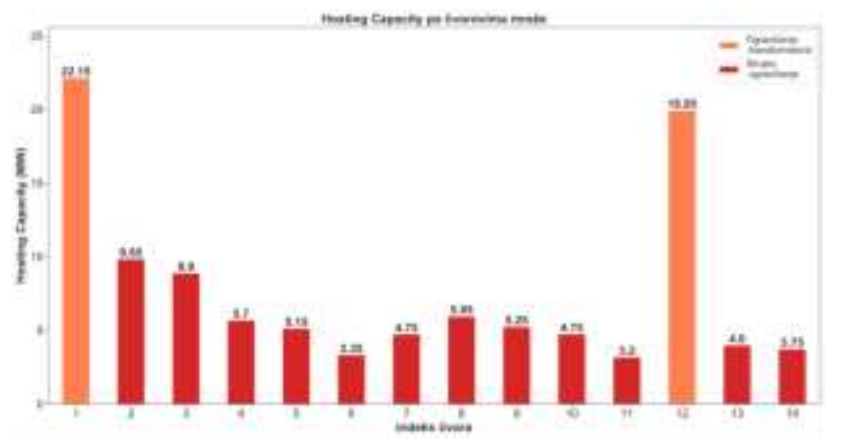

Slika 4.3 Hosting Capacity po čvorovima mreže za primer 2

U ovom primeru dobijene su dosta veće vrednosti Hosting Capacity-a po čvorovima mreže, jer je potrošnja maksimalna, a proizvodnja minimalna. Samim tim, snaga će se uzimati iz mreže i teći ka nižem naponu, što opterećuje vodove i najčešće dolazi do narušavanja strujnog ograničenja. U čvorovima 1 i 12 će, kao i u prethodnom primeru, najpre doći do narušavanja ograničenja transformatora.

\section{Primer 3}

U ovom primeru se računa Hosting Capacity po svim čvorovima mreže. Generatori rade sa jediničnim faktorom snage. Proračun se vrši za različite kombinacije proizvodnji i potrošnji koje se biraju primenom Monte Carlo metode. Ograničenja napona su $\pm 5 \%$, dok su strujna i ograničenje transformatora $100 \%$. Rezultati proračuna po čvorovima prikazani su na slici 4.4 .

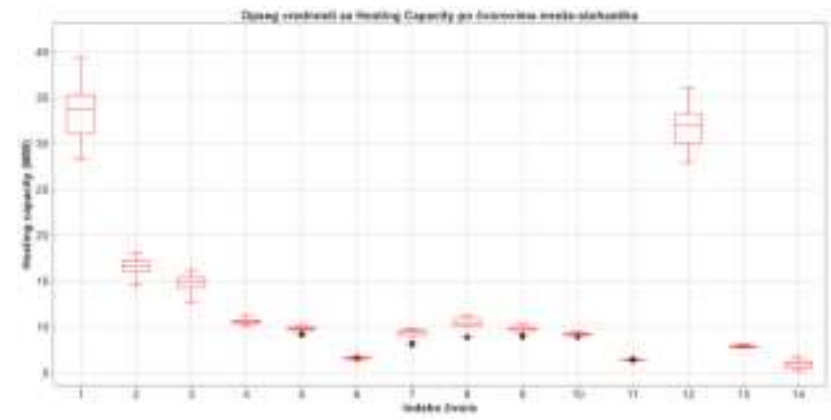

Slika 4.4 Opseg vrednosti za Hosting Capacity po čvorovima mreže

Može se primetiti da su vrednosti Hosting Capacity-a po svakom čvoru predstavljene kao opseg različitih vrednosti, jer su proračuni rađeni za različita stanja mreže, ali su i vrednosti mnogo veće, jer su dozvoljena ograničenja veća.

Nakon što se odredi Hosting Capacity po čvorovima mreže, moguće je odrediti i Hosting Capacity po fiderima, za šta su se koristile minimalne vrednosti Hosting Capacity-a po svim čvorovima mreže. Rezultati se mogu videti na slici 4.5, a u tabeli 4.1 su predstavljenje vrednosti Hosting Capacity-a fidera po različitim regijama.

Tabela 4.1 HC po fiderima mreže za primer 3

\begin{tabular}{|c|c|c|c|}
\hline Regija & $\begin{array}{c}\text { Regija A } \\
\text { Min HC } \\
(\mathrm{MW})\end{array}$ & $\begin{array}{c}\text { Regija B } \\
\text { HC } \\
(\mathrm{MW})\end{array}$ & $\begin{array}{c}\text { Regija C } \\
\text { Max HC } \\
(\mathrm{MW})\end{array}$ \\
\hline F1 & 6.33 & 8.83 & 28.31 \\
\hline F2 & 5.17 & 7.76 & 27.90 \\
\hline
\end{tabular}

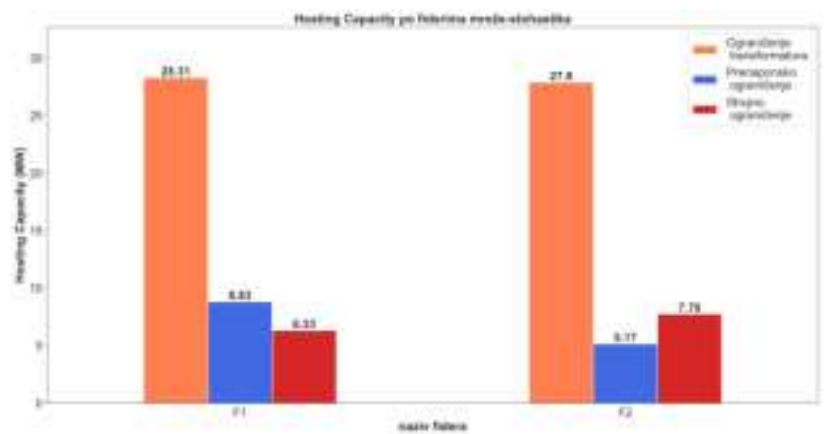

Slika 4.5 Hosting Capacity po fiderima mreže za primer 3

\section{ZAKLJUČAK}

Hosting Capacity nije pojedinačna vrednost koja se može izračunati jednom. Trebalo bi ga redovno proveravati za različite indekse performansi. Treba odrediti minimalnu vrednost Hosting Capacity po svakom čvoru za procenu Hosting Capacity-a fidera ili sistema. Minimalni Hosting Capacity se dobija pri maksimalnoj proizvodnji i minimalnoj potrošnji, dok se maksimalni Hosting Capacity dobija pri minimalnoj proizvodnji i maksimalnoj potrošnji. Hosting Capacity je, takođe, koncept koji zavisi od lokacije na kojoj se DG priključuje. Drugim rečima, što je čvor bliže transformatoru, jača je njegova sposobnost za priključivanje veće količine DG-a, odnosno, veći je Hosting Capacity. Obično se previsoki naponi javljaju kada su DG povezani na većim udaljenostima od trafostanica, gde je veći porast napona. Preopterećenje mrežnih komponenata, kao što su vodovi i transformatori, postaje ograničavajući faktor kada su DG priključeni blizu trafostanice tako da previsok napon nije problem.

\section{LITERATURA}

[1] M. Bollen, F. Hassan: „Integration of distributed generation in the power system", IEEE Press, John Wiley \& Sons, Inc., Hoboken, New Jersey, 2011.

[2] N. Etherden, M.H.J. Bollen, S. Ackeby, O. Lennerhag, „The transparant hosting capacity approach - overview, applications and developments", The 23-rd Int. Conf. Electr. Distrib., 2015, pp. 1e5.

[3] C. Antonakopoulos: „Investigation of the distribution grid hosting capacity for distributed generation and possible improvements by Smart Grid technologies", Master Thesis, Zurich, September 2016

[4] M. Seidaliseifabad: „Hosting capacity assessment of distribution systems", PhD Dissertation, Faculty of Engineering and Information Technology The University of Sydney, March 2020.

[5] CIGRE, Benchmark systems for network integration of renewable and distributed energy resources. Task Force C6.04.02, 2014. ISBN: 978-285-873-270-8.

\section{Kratka biografija:}

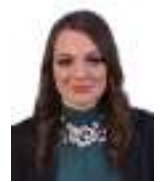

Nataša Ljubojev rođena je u Tuzli 1992. god. Master rad na Fakultetu tehničkih nauka iz oblasti Elektrotehnike i računarstva - Elektroenergetski sistemi odbranila je 2021.god.

kontakt: natasa992@gmail.com 